\title{
Relationship-specific investment and hold-up problems in supply chains: theory and experiments
}

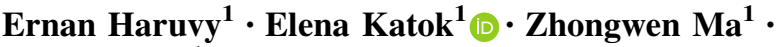 \\ Suresh Sethi ${ }^{1}$
}

Received: 5 April 2018/ Accepted: 25 June 2018/Published online: 20 July 2018

(C) The Author(s) 2018

\begin{abstract}
Supply chains today routinely use third parties for many strategic activities, such as manufacturing, $R \& D$, or software development. These activities often include relationship-specific investment on the part of the vendor, while final outcomes can be uncertain. Therefore, writing complete contracts for such arrangements is often not feasible, but incomplete contracts, especially when relationship-specific investment is required, may leave the supplier vulnerable to a version of the "hold-up problem," which is known to result in sub-optimal levels of investment. We model the phenomenon as a sequential move game with asymmetric information. Absent behavioral considerations, the unique Perfect Bayesian Equilibrium implies zero investment. However, with social preferences, the hold-up problem may be mitigated. We propose a model that incorporates social preferences and random errors, and solve for the equilibrium. In addition, we look at reputation and find it to be effective for increasing investment. We conduct laboratory experiments with human subjects and find that a model with social preferences and random errors organizes our data well.
\end{abstract}

Keywords Supply chain contracts - Behavioral economics - Game theory

\section{Elena Katok}

ekatok@utdallas.edu

Ernan Haruvy

eharuvy@utdallas.edu

Zhongwen Ma

dallasowenma@gmail.com

Suresh Sethi

sethi@utdallas.edu

1 Naveen Jindal School of Management, University of Texas at Dallas, Richardson, TX 75080, USA 


\section{Introduction}

\subsection{Theoretical and Empirical Background}

Today, firms increasingly rely on third party vendors for many strategic activities, including manufacturing. For example, The New York Times reported that "...almost all of the 70 million iPhones, 30 million iPads and 59 million other products Apple sold last year were manufactured overseas." (Duhigg and Bradsher 2012). Reliance on vendors for performing strategic activities, such as the manufacturing of products using proprietary technology, creates a number of pitfalls. One of the major pitfalls, and the focus of our paper, has to do with a version of the hold-up problem.

The hold-up problem (Rogerson 1992) emerges when one firm in a relationship is able to expropriate the returns from an investment made by another firm (for a discussion on the ability of a firm to appropriate value, see MacDonald and Ryall 2004). Specifically, if one firm makes an investment that has a low value outside of the relationship, that firm is vulnerable to being "held up" for the value of that relationship-specific investment. The hold-up problem is particularly likely to emerge in settings in which writing complete contracts is not feasible due to some combination of information asymmetry and environmental uncertainty (Rogerson 1992). It has long been argued in the economics literature (see Coase 2006 for an overview) that the presence of a potential hold-up problem results in underinvestment in relationship-specific investments leading to inefficiency, and so the ability to mitigate the hold-up problem has potential value.

Crocker and Reynolds (1993) describe an interesting example from the 1970s dealing with government procurement. The US military made a significant investment in Research \& Development (R\&D) for production of jet engines for F-15 and F-16 fighter. The military was working with Pratt \& Whitney as a sole source supplier on this project. As the sole supplier, Pratt was in a strong position to hold up the US military by demanding excessive concessions to correct quality problems. As a result, in 1979 the Air Force commissioned General Electric to develop a functionally equivalent jet engine for the use in its B-1 bomber. This resolved the hold-up problem and the number of contract disputes decreased, but at the cost of funding a second engine by the US Military. The US Congress has continued to fund the two engines through 2011 (Schone 2011).

Other examples of negative and costly consequences that have the hold-up flavor include expensive and protracted lawsuits, such as one between the U.S. Postal Service and Northrop-Grumman Corp., whose contract dispute led to over $\$ 500$ million in lawsuits (Reilly 2012). Fears of the hold-up problem, on the other hand, result in under-investment by suppliers (Haruvy et al. 2012), leading to Original Equipment Manufacturers (OEMs) being unable to fill lucrative contracts. Barnes (2012) describes Boeing's situation of being unable to fill orders worth billions of dollars for many years due to its suppliers' inability or unwillingness to invest in required capacity. 


\subsection{Experimental literature on the hold-up problem}

We study incomplete contracts that make one of the players vulnerable to a version of the hold-up problem, using laboratory experiments with human subjects. In the experimental economics literature, the hold-up problem builds on the extensively studied investment game (Berg et al. 1995). In the investment game, the first mover - the seller (the terms seller and buyer are accepted terminology, e.g., Hoppe and Schmitz 2011) - decides whether to invest in production. Investment creates surplus (generally in investment game experiments, the surplus to be divided is three times the investment amount-a parameterization not required for the definition of an investment game). The second mover-the buyer-decides how much of the created surplus to expropriate. There is much room for mutual gain of both parties, but given the sequential nature of the game, it is best response of the buyer to expropriate the entire surplus in a single shot game. By backward induction, the seller will not invest. In numerous experimental studies (see overview in Camerer 2003), the general pattern is that sellers do invest and buyers share some of the surplus with the sellers.

The setting that we study in this paper is different from the standard investment game in several aspects. One aspect is that the seller has the last word and can accept or reject the buyer's offer. In Dufwenberg et al. (2013), two variations were studied. In the first, the "Low game," the first mover could reject an unkind surplus division, resulting in a loss to both himself and the second mover. In the second, the "High game," rejection would actually improve the outcome for the buyer, and thus may not be useful as a threat. As expected, none of the sellers who decided to initially produce chose to reject an unkind offer that results in a gain to the buyer. Even in this High game version, there is investment (40\%) by the seller, which is difficult to justify in an equilibrium sense. The authors also report that the vast majority of buyers (90\%) in fact did choose the unkind surplus division, which makes the fact that $40 \%$ of the sellers chose to invest particularly surprising.

Ellingsen and Johannesson (2004a) run a hold-up game experiment as well (using the term hold-up), to study the effect of communication. Their interpretation of what constitutes a hold-up game is the same as Dufwenberg et al. The seller (their terminology has seller and buyer) first decides whether to invest 60 or not. Then, the buyer proposes a division of 100 tokens, which is the revenue created by the investment. The seller can then accept or reject. This structure is the same as Dufwenberg et al. with somewhat different payoffs. The purpose of the experiment was to compare the basic treatment to communication treatments with promises by the buyers or threats by the seller. They found that communication did in fact mitigate the hold-up problem. An important companion to Ellingsen and Johannesson (2004a) is Ellingsen and Johannesson (2004b). A key difference between these two studies is that bargaining in the latter is not in ultimatum format. In that design, each of the two agents makes a claim. The revenue is equal to 0 if the sum of the claims exceeds 100. If the sum of the claims is 100 or less, each subject gets his claim (i.e., bilateral bargaining according to Nash's demand game, Nash 1953). Other than that, the experimental designs are largely identical. Ellingsen and Johannesson (2004a) find that communication mitigates the hold-up problem. 
Specifically, unilateral communication—by buyer or seller—facilitates coordination and increases investment.

Hoppe and Schmitz (2011) study the effect of contracting on the hold-up game. They find that option contracts improve performance. Unlike Dufwenberg, they add a participation decision in which either party can decide to decline participating in the game. After that stage, the game has the same structure as Dufwenberg et al. (2013): The seller makes an investment decision ( 0 or 8$)$. The buyer then learns the investment decision and makes a take-it-or-leave-it price offer. The seller can then take it or leave it. If he leaves it, he forgoes the cost of the investment-thus the hold-up. Hoppe and Schmitz model all contract decisions as eliminating one of the stages and thus reducing the hold-up problem to an investment problem. In the fixed price contract, the buyer's pricing decision and the seller's final accept/reject decisions go away and the problem becomes equivalent to an investment/trust game with the buyer moving first, choosing to pay the seller or not. If he pays, he has to trust the seller to make the investment and not to expropriate the surplus. In the option contract, the seller invests without the option of accepting or rejecting. They also investigated a contract with renegotiation which is similar in spirit to the communication study of Ellingsen and Johannesson (2004a) described above.

Davis and Leider (2013), similar to Hoppe and Schmitz (2011), study the possibility that an option contract mitigates the holdup problem. In the option contract, the retailer and supplier agree ex ante to buy and sell units up to $D$ units at a wholesale price of $w$ and the retailer pays a lump sum option fee to the supplier. The framework is different in that the first mover makes a capacity investment, demand is random, and bargaining is structured. Bargaining is such that both roles have the ability to make multiple back-and-forth offers while also providing feedback on the offers they receive. They find that the option contract does indeed mitigate the hold-up problem. They further find that the evolution of offers during bargaining suggests "superficial fairness." Specifically, wholesale price falls in the middle of the available contracting space, away from the coordinating contract parameter.

There are other studies that model settings that are closer to the theoretical holdup problem, without invoking the term. In Hackett (1994) experiment, for example, two players decide on respective investments that increase joint surplus but also increase individual cost. They then realize a probabilistic outcome that depends on the investments and then bargain over the joint surplus, with either party having a veto power. Hackett (1994) finds that the surplus division is responsive to the investments. The setting is closer to the theoretical literature in that the unknown realization of the eventual outcome makes the contract incomplete-unlike the settings of Dufwenberg et al. (2013) and Hoppe and Schmitz (2011).

The key innovation in the setting we study, that distinguishes it from the literature we summarized above, is the presence of asymmetric information. Asymmetric information makes designing a "better contract" less plausible because contingent contracts may be impossible to enforce. So the asymmetric information aspect in our study is important for practice, and new in terms of research focus. 


\subsection{Behavioral contribution}

It has been shown in experimental economics, as well as in the behavioral operation management literature, that people are not motivated exclusively by monetary payoffs - they have social preferences (see Cooper and Kagel 2015; Loch and Wu 2008; Katok and Pavlov 2013). A stream of theoretical works investigates social preferences, such as inequality aversion, in the context of the hold-up problem (Gantner et al. 1998, Oosterbeek et al. 1999; Sonnemans et al. 2001; von Siemens 2009). Dufwenberg et al. (2013) argue that the patterns observed in the hold-up problem are explained by reciprocity. We use a behavioral model to analyze the hold-up problem, but our behavioral model uses inequality aversion (Bolton and Ockenfels 2000; Fehr and Schmidt 1999; Cui et al. 2007). We further solve the problem in a dynamic framework, whereas Dufwenberg et al. (2013) analyze the one-shot setting. We analyze the dynamics by approximating a dynamic setting in our experiments and refer to this as dynamic approximation.

Thus, our solution concept involves a tradeoff. On the one hand, it is quite broad, which allows us to use it for testing a model that does not rely on reciprocity preferences and generalizing the solution to dynamic environments. On the other hand, our approach involves an approximation that captures how people think about the uncertain future actions of others. We think this approximation is reasonable and is a good first step to understanding behavior in repeated settings.

Our second behavioral contribution is a demonstration that reputation information can help solve the hold-up problem. Reputation may serve in lieu of informal agreements (Hart et al. 2013). Board (2011) shows that theoretically, even in the presence of many potential partners, an optimal contract design implies loyalty to existing partners. ${ }^{1}$ Bolton et al. (2004) show that reputation increases both trust and trustworthiness. They also report that, contrary to standard theory, some cooperation exists even without a formal feedback mechanism. This argument is also consistent with the findings by Özer et al. (2011) that people are more truthful than the standard theory predicts. Özer et al. (2013) refine these findings and extend them to a multi-cultural setting. Our work complements these earlier findings by showing that some cooperation is consistent with the dynamic equilibrium approximation in a repeated setting with a finite number of players. More importantly, we show that even though the dynamic approximation analysis is only an approximation for the actual setting in our experiment, it predicts the outcomes remarkably well.

\footnotetext{
1 The proof hinges on grim-trigger punishment in an infinitely repeated game. Once a partner defects, investment is zero forever after a certain period. The setting is not at all like ours because the principal has multiple partners to choose from, and a rich space of repeated game strategies to employ, but the idea of the game being more than a one-shot is an important component of the present setting, as well as the concept of reputation.
} 


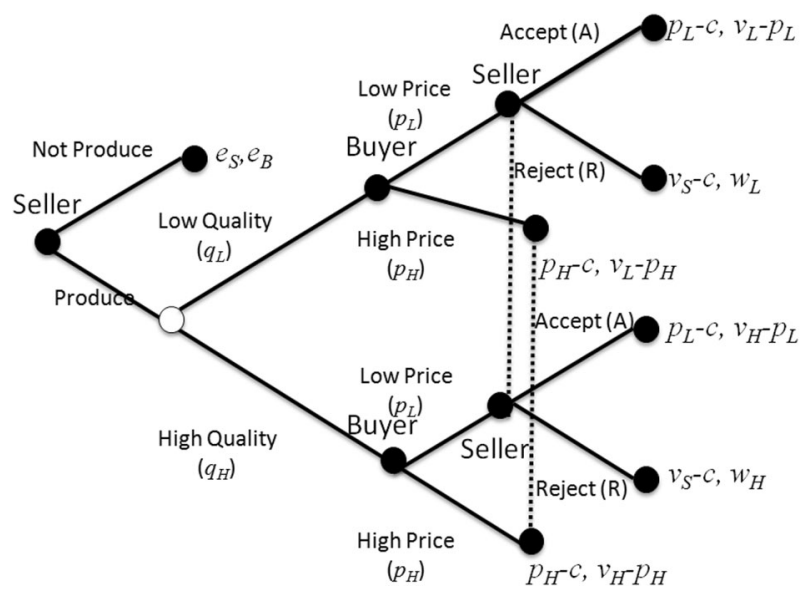

Fig. 1 Extensive form game

\section{Model}

In this section, we describe the basic game setting used in our study. We show that if players are motivated exclusively by monetary payoffs, the hold-up problem is severe. We then proceed to extend the model to include social preferences and random errors, and develop the dynamic equilibrium approximation that can predict that these behavioral considerations may mitigate the hold-up problem.

\subsection{The game and standard model}

We begin with the basic setting, which is a sequential game with asymmetric information. The standard analysis assumes that players care exclusively about their monetary payoffs. We then proceed to add social preferences and random errors. Figure 1 displays the extensive form of the game we analyze.

The seller moves first and decides whether to produce or not produce. If the seller chooses not to produce, then the buyer and the seller earn their outside option payoffs $e_{\mathrm{B}}$ and $e_{\mathrm{S}}$, respectively. If the seller chooses to produce, product quality is $q_{\mathrm{L}}$ with probability $\delta=P\left(q_{\mathrm{L}}\right)$ and $q_{\mathrm{H}}$ with probability $1-\delta=P\left(q_{\mathrm{H}}\right)=1-P\left(q_{\mathrm{L}}\right)$.

Quality is privately known to the buyer. ${ }^{2}$ That is, the seller does not know the quality while the buyer does. In the context of the buyer being an end consumer, this is a straightforward assumption. The end consumer knows whether he likes the product and finds it esthetically pleasing, functional, fitting, or satisfying. The seller does his best to satisfy the consumer but if the consumer claims to be dissatisfied the seller cannot verify whether this claim is correct. In a supply chain context, this motivation extends to downstream channel members. The closer a channel member is to the end consumer, the more knowledge he has regarding end customer

\footnotetext{
${ }^{2}$ In the experiment, the buyer is told realized quality.
} 
satisfaction, customer returns, malfunctions, customer service calls, warranty claims, customer reviews, customer churn, etc. Thus, the buyer possesses information about quality that the seller does not.

The value of high-quality product to the buyer is $v_{\mathrm{H}}$ and the value of low-quality product to the buyer is $v_{\mathrm{L}}$. Upon observing quality, the buyer decides to offer either high price $p_{\mathrm{H}}$ or low price $p_{\mathrm{L}}$. In the last stage of the game, the seller decides whether to accept or reject the buyer's price. If the seller accepts price $p_{k}$, $k \in\{H, L\}$, then the seller earns $p_{k}-c$ and the buyer earns $v_{\mathrm{H}}-p_{k}$ if quality was high or $v_{\mathrm{L}}-p_{k}$ if quality was low. If the seller rejects $p_{\mathrm{L}}$ (in Fig. 1 we assume that the seller never rejects the high price), then the seller earns $v_{\mathrm{S}}-c$, where $v_{\mathrm{S}}$ is the value of the product to the seller outside of the relationship, and the buyer earns $w_{\mathrm{L}}$ when $q=q_{\mathrm{L}}$ and $w_{\mathrm{H}}$ when $q=q_{\mathrm{H}}$. Note that the innovation in our game is the presence of incomplete information: the buyer learns the product quality, and the seller does not.

The hold-up problem emerges when two conditions hold:

1. The seller's profit from accepting a low price is higher than from rejecting: $p_{\mathrm{L}}>v_{\mathrm{S}}$.

2. The seller's profit from the outside option is between expected profit from low price and expected profit from high price for high quality: $p_{\mathrm{L}}-c<e_{\mathrm{S}}<\left(\delta p_{\mathrm{L}}-(1-\delta) p_{\mathrm{H}}\right)-c$.

Condition 1 ensures that after producing, the seller will not reject the low price. Knowing this implies that in a single-shot game, the buyer has a dominant strategy to offer low price regardless of quality. Condition 2 ensures that the seller will not produce under these circumstances.

Additionally, if the buyer's outside option is higher than the net profit from paying high price for low quality, $e_{\mathrm{B}}>v_{\mathrm{L}}-p_{\mathrm{H}}$, the parties are likely to be unable to contract at high price prior to the production decision because such a contract would not be ex post rational for the buyer. But if the buyer earns higher profit from paying high price for high quality and low price for low quality than from his outside option: $\delta\left(v_{\mathrm{L}}-p_{\mathrm{L}}\right)+(1-\delta)\left(v_{\mathrm{H}}-p_{\mathrm{H}}\right)>e_{\mathrm{B}}$, then there are positive gains from trade-if the parties could overcome the hold-up problem, they would both potentially be better off. We summarize the analysis of a single-shot game with profit-maximizing players as Proposition 1.

Proposition 1 (The hold-up problem) when conditions 1-2 are satisfied, the game is single shot, and players care exclusively about their monetary payoffs, the buyer will never offer a high price and the seller will never produce.

Proof Sellers will not reject a low price due to condition (1). Buyers will not offer a high price in the single-shot game when they are motivated solely by monetary payoffs. Offering a low price in this setting is a dominant strategy. Sellers will not produce due to condition (2). 


\subsection{Social preferences}

We will apply to the game in Fig. 1 a simplified version of the inequality aversion model by Bolton and Ockenfels (2000) that has been extended to a supply channel setting by Cui et al. (2007).

Consider a linear version of the Bolton and Ockenfels (2000) and Fehr and Schmidt (1999) model in which player $i$ derives negative utility when her profit is below some fair outcome in terms of the relative difference between her and player $j$ 's profit. Player $i$ 's utility can be written as:

$$
u_{i}=\pi_{i}-\alpha\left(\gamma \pi_{j}-\pi_{i}\right)^{+}-\beta\left(\pi_{i}-\gamma \pi_{j}\right)^{+},
$$

where $\alpha$ is player $i$ 's degree of disadvantageous inequality aversion (negative utility from earning less than some relative fair share $\gamma$ ), and $\beta$ is $i$ 's degree of advantageous inequality aversion. Parameter $\gamma$ represents the share of the channel profit that player $j$ earns under profit distribution that is considered to be fair ( $\gamma$ may reflect differences in initial investment or other value-added activities; see Cui et al. 2007).

In the rest of the paper, we will set $\gamma=1$ because it is reasonable for our laboratory setting and will simplify notation. For the same reasons, we will also make the simplifying assumption $\beta=0$. The assumption of $\gamma=1$ means that player $i$ considers the fair allocation to be at the point where the profits of both players are exactly equal. Cui and Mallucci (2016) experimentally evaluated an environment structured similarly to ours in that there is a two-stage dyadic channel, in which firms decide on investments in the first stage and then on prices in the second stage. Their utility specification is identical to our utility Eq. (1), with only a slight notation difference. Specifically, they denote $\tau /(1-\tau)$ for our $\gamma$. They note that $\tau=\frac{1}{2}(\gamma=1$ in our notation) corresponds to the strict egalitarian ideal.

They also proposed a "sequence-aligned" notion of fairness in their framework which corresponds to the share of the decision maker in their framework under the Stackelberg equilibrium. In their setting, this notion prescribed $\tau=\frac{1}{3}$. In our experiment, the equilibrium is for no production to take place, and both players earn equal outside payoffs of 2 , resulting in a sequence-aligned prescription of $\tau=\frac{1}{2}$ $(\gamma=1$ in our notation), identical to the egalitarian notion. Our study thus does not distinguish these fairness notions, as they both prescribe $\gamma=1$.

Incidentally, Cui and Mallucci (2016) found that the sequence-aligned notion of fairness fits their data better than the strict egalitarian value, and this is consistent with $\gamma=1$ in our framework. They also conclude that $\beta=0$ which we rely on as support for our own $\beta=0$ assumption.

The simplified seller's utility function then becomes

$$
u_{\mathrm{S}}=\pi_{\mathrm{S}}-\alpha\left(\pi_{\mathrm{S}}-\pi_{\mathrm{B}}\right)^{+},
$$

and it will be used in the rest of the paper.

The main effect of inequality aversion on the seller has to do with the seller's reaction to low price. With inequality aversion, the seller needs to form a belief about the buyer's payoff, meaning that he has to form a belief about quality which he does not observe. Specifically, the seller does not know quality realization but 
can form a belief about quality conditional on the price he was offered. The critical piece of information that the seller would like to know when he is offered a low price is whether this was due to low quality or not. In other words, the seller would like to know $P\left(q_{\mathrm{L}} \mid p_{\mathrm{L}}\right)$. We assume that the seller knows the unconditional probability of being offered a high price, $P\left(p_{\mathrm{H}}\right)$ (for example, based on historical data), and then uses Bayes' rule to calculate conditional probabilities. We further assume that high price for low quality is dominated for the buyer so that $\left.P\left(p_{\mathrm{H}} \mid q_{\mathrm{L}}\right)=0\right)$. This gives us

$$
P\left(q_{\mathrm{L}} \mid p_{\mathrm{L}}\right)=\frac{P\left(p_{\mathrm{L}} \mid q_{\mathrm{L}}\right) P\left(q_{\mathrm{L}}\right)}{P\left(p_{\mathrm{L}}\right)}=\frac{P\left(q_{\mathrm{L}}\right)}{P\left(p_{\mathrm{L}}\right)}=\frac{\delta}{1-P\left(p_{\mathrm{H}}\right)} .
$$

We assume that the seller operates in the environment of being subject to disadvantageous inequality only. The seller's expected utilities from accepting and rejecting a low price are

$$
\begin{aligned}
\mathbb{E}\left[u_{\mathrm{S}}\left(p_{\mathrm{L}}, A\right)\right]= & p_{\mathrm{L}}-c-\alpha\left[\left(1-\frac{\delta}{1-P\left(p_{\mathrm{H}}\right)}\right)\left(v_{\mathrm{H}}-p_{\mathrm{L}}\right)+\left(\frac{\delta}{1-P\left(p_{\mathrm{H}}\right)}\right)\left(v_{\mathrm{L}}-p_{\mathrm{L}}\right)-\left(p_{\mathrm{L}}-c\right)\right]^{+}, \\
& \mathbb{E}\left[u_{\mathrm{S}}\left(p_{\mathrm{L}}, R\right)\right]=v_{\mathrm{S}}-c-\alpha\left[\left(1-\frac{\delta}{1-P\left(p_{\mathrm{H}}\right)}\right) w_{\mathrm{H}}+\left(\frac{\delta}{1-P\left(p_{\mathrm{H}}\right)}\right) w_{\mathrm{L}}-\left(v_{\mathrm{S}}-c\right)\right]^{+} .
\end{aligned}
$$

Consider the terms in Eq. (3) that multiply $\alpha$. These terms represent potential loss in utility to the seller due to being relatively worse off than the buyer. If $v_{\mathrm{S}}<p_{\mathrm{L}}$ (according to Condition 1), which is a reasonable assumption for a setting in which the seller makes a relationship-specific investment, then rejecting a low price makes the seller worse off in absolute terms. If it is also the case that

$$
\begin{aligned}
& {\left[\left(1-\frac{\delta}{1-P\left(p_{\mathrm{H}}\right)}\right)\left(v_{\mathrm{H}}-p_{\mathrm{L}}\right)+\left(\frac{\delta}{1-P\left(p_{\mathrm{H}}\right)}\right)\left(v_{\mathrm{L}}-p_{\mathrm{L}}\right)-\left(p_{\mathrm{L}}-c\right)\right]^{+}} \\
& <\left[\left(1-\frac{\delta}{1-P\left(p_{\mathrm{H}}\right)}\right) w_{\mathrm{H}}+\left(\frac{\delta}{1-P\left(p_{\mathrm{H}}\right)}\right) w_{\mathrm{L}}-\left(v_{\mathrm{S}}-c\right)\right]^{+},
\end{aligned}
$$

then rejecting makes the seller worse off in relative terms as well, and consequently the seller has no reason to reject, and the buyer can offer low prices with impunity. We call (4) the impunity condition.

Proposition 2 (Reciprocity) If the impunity condition (4) does not hold and the buyer earns higher profit from high price for high quality than from a rejection ( $\left.v_{\mathrm{H}}-p_{\mathrm{H}}>w_{\mathrm{H}}\right)$, the buyer motivated exclusively by profit may offer high price for high quality in the single-shot game if the seller has sufficiently high $\alpha$. A seller with sufficiently high $\alpha$ will produce.

Proof If condition (4) does not hold, it means that there exists a high enough $\alpha$ that the seller with this $\alpha$ will have higher utility from rejecting than from accepting a low price. Therefore, this seller may reject a low price. Since $v_{\mathrm{H}}-p_{\mathrm{H}}>w_{\mathrm{H}}$, the buyer will offer high price for high quality. Since $p_{\mathrm{H}}-c>e_{\mathrm{S}}$, the seller will produce. 


\subsection{Incorporating errors}

It has been shown that laboratory participants make random errors ( $\mathrm{Su}$ 2008). It is useful to incorporate these random errors into the analysis to obtain better estimates of behavioral parameters. We follow the basic idea of a logistic mapping between expected utilities and action probabilities (e.g., McKelvey and Palfrey 1995). It implies that people are more likely to choose an action that yields higher expected utility.

Our goal here is to construct a parsimonious model that captures the essential aspects of the problem setting. The critical aspects of the problem setting are the ones that result in the hold-up problems: (1) the seller is financially better off to not produce unless there is a sufficient likelihood that the buyer will offer high price for high quality, and (2) in the long run, the buyer is much better off if the seller produces, even if he has to induce production by sometimes paying high prices for high quality. So the buyer and the seller face fundamentally different problems.

The seller will only produce if he expects to see a high price with sufficiently high probability. It is reasonable to model a seller as if he is playing a game in which he is using information from past rounds to forecast the probability $P\left(p_{\mathrm{H}}\right)$ but is not attempting to affect the future behavior of the buyers. In contrast, the buyer is facing a clear tradeoff each period between the immediate payoff from paying low price for high quality and the loss from lack of production by suppliers in future rounds. Therefore, we approximate buyers' behavior with a model in which buyers decide on a fixed probability of offering high price for high quality given the sellers' response function and the behavior of other buyers in the market. ${ }^{3}$ That is, sellers need to form beliefs given the history of the game, whereas buyers need to develop reputations (individually or as a group) to make it desirable for sellers to produce. This framework results in simple theoretical benchmarks that capture most of the regularities of the data in our laboratory experiments.

\subsubsection{The sellers}

We model the seller's probability of producing as a logit function (McKelvey and Palfrey 1995). ${ }^{4}$

$$
P(\text { Produce })=\frac{\exp \left(\tau \mathbb{E}\left[u_{\mathrm{S}}(\text { Produce })\right]\right)}{\exp \left(\tau e_{\mathrm{S}}\right)+\exp \left(\tau \mathbb{E}\left[u_{\mathrm{S}}(\text { Produce })\right]\right)},
$$

where $\tau$ is the rationality parameter and

\footnotetext{
${ }^{3}$ The model of buyers we propose is parsimonious, and we do not argue that it is "the right model" but merely a very simple one that has a chance of being consistent with the data. For example, Özer, Zheng and Chen (2011) propose a model in which retailers, faced with a problem that has similar features to ours, are averse to lying. Additionally, buyers could make random errors, which would not affect qualitative predictions, but in all likelihood would make the model fit the data even better.

${ }^{4}$ In this section, we are analyzing the repeated game equilibrium approximation under the assumption that sellers are ex ante symmetric, and therefore we do not subscript sellers' decisions either by time subscript $t$ or seller subscript $j$. In the estimation section, in which we use the panel data from our experiment, we will add subscripts for seller $j$ and time period $t$ to our notation.
} 


$$
\begin{aligned}
\mathbb{E}\left[u_{\mathrm{S}}(\text { Pr oduce })\right]= & P\left(p_{\mathrm{H}}\right) \mathbb{E}\left[u_{\mathrm{S}}\left(p_{\mathrm{H}}, A\right)\right] \\
& +\left(1-P\left(p_{\mathrm{H}}\right)\right)\left[P\left(p_{\mathrm{L}}, A\right) \mathbb{E}\left[u_{\mathrm{S}}\left(p_{\mathrm{L}}, A\right)\right]+P\left(p_{\mathrm{L}}, R\right) \mathbb{E}\left[u_{\mathrm{S}}\left(p_{\mathrm{L}}, R\right)\right]\right] .
\end{aligned}
$$

If the seller's decision to reject is not dominated, then we start with the seller's decision to accept or reject a low price. The seller's expected utility from accepting a low or a high price works out to be

$$
\mathbb{E}\left[u_{\mathrm{S}}\left(p_{\mathrm{L}}, A\right)\right]=p_{\mathrm{L}}-c-\alpha\left(\left(1-\frac{\delta}{1-P\left(p_{\mathrm{H}}\right)}\right)\left(v_{\mathrm{H}}-v_{\mathrm{L}}\right)+v_{\mathrm{L}}-2 p_{\mathrm{L}}+c\right)^{+}
$$

and

$$
\mathbb{E}\left[u_{\mathrm{S}}\left(p_{\mathrm{H}}, A\right)\right]=p_{\mathrm{H}}-c-\alpha\left(v_{\mathrm{H}}-2 p_{\mathrm{H}}+c\right)^{+} .
$$

To keep the problem tractable, we assume $v_{\mathrm{L}}-p_{\mathrm{L}}>p_{\mathrm{L}}-c$, meaning that the term inside the parentheses in the expression for $\mathbb{E}\left[u_{\mathrm{S}}\left(p_{\mathrm{L}}, A\right)\right]$ in Eq. (6) is positive.

Meanwhile, the seller's expected utility from rejecting either a low or a high price is

$$
\mathbb{E}\left[u_{\mathrm{S}}\left(p_{\mathrm{L}}, R\right)\right]=\mathbb{E}\left[u_{\mathrm{S}}\left(p_{\mathrm{H}}, R\right)\right]=v_{\mathrm{S}}-c-\alpha\left(v_{\mathrm{B}}(q)-\left(v_{\mathrm{S}}-c\right)\right)^{+} .
$$

It follows that the probability of accepting price $p_{k}$ is

$$
P\left(p_{k}, A\right)=\frac{\exp \left(\tau \mathbb{E}\left[u_{\mathrm{S}}\left(p_{k}, A\right)\right]\right)}{\exp \left(\tau \mathbb{E}\left[u_{\mathrm{S}}\left(p_{k}, A\right)\right]\right)+\exp \left(\tau \mathbb{E}\left[u_{\mathrm{S}}\left(p_{k}, R\right)\right]\right)}, \quad k \in\{H, L\} .
$$

\subsubsection{The buyers}

Let us assume that there are $n$ buyers in the market, randomly matched with $n$ sellers, but the number of periods is large relative to $n$ so that after some number of periods, sellers assume that $P\left(p_{\mathrm{H}}\right)$ in the current period will follow the probability distribution of the past $P\left(p_{\mathrm{H}}\right)$. We assume full information, which means that $P\left(p_{\mathrm{H}}\right)$ forecasted by sellers, $\delta=P\left(q_{\mathrm{L}}\right)$, as well as sellers' $\alpha$ and $\tau$, are all known to buyers. This means that buyers know (5) and (7) - the sellers' probabilities of future production and of rejecting a low price.

Each buyer $i$ maximizes her expected long run average profit by choosing $P_{i}\left(p_{\mathrm{H}} \mid q\right)$ where $q \in\left\{q_{\mathrm{L}}, q_{\mathrm{H}}\right\}$.

$$
\max _{P_{i}\left(p_{\mathrm{H}} \mid q\right)} \mathbb{E}\left[u_{\mathrm{B}}\left(P_{i}\left(p_{\mathrm{H}} \mid q\right)\right)\right]
$$

where

$$
\begin{aligned}
\mathbb{E}\left[u_{\mathrm{B}}\left(P_{i}\left(p_{\mathrm{H}} \mid q\right)\right)\right]= & P(\text { Produce })\left\{\delta \mathbb{E}\left[u_{\mathrm{B}}\left(P_{i}\left(p_{\mathrm{H}} \mid q_{\mathrm{L}}\right)\right)\right]+(1-\delta) \mathbb{E}\left[u_{\mathrm{B}}\left(P_{i}\left(p_{\mathrm{H}} \mid q_{\mathrm{H}}\right)\right)\right]\right\} \\
& +(1-P(\text { Produce })) e_{\mathrm{B}},
\end{aligned}
$$

and $P$ (Produce) is defined by (5) and in the long run depends on $P\left(p_{\mathrm{H}}\right)$ observed by the seller. Note that $P\left(p_{\mathrm{H}}\right)$ is based on the behavior of all $n$ buyers, so each buyer $i$ has an effect on the average $P\left(p_{\mathrm{H}}\right)$ that a seller observes.

If the buyer never pays high price for low quality, so $P_{i}\left(p_{\mathrm{H}} \mid q_{\mathrm{L}}\right)=0$, then the buyer's expected utility when he observes low quality is 


$$
\mathbb{E}\left[u_{\mathrm{B}}\left(P_{i}\left(p_{\mathrm{H}} \mid q_{\mathrm{L}}\right)\right)\right]=P\left(p_{\mathrm{L}}, A\right)\left(v_{\mathrm{L}}-p_{\mathrm{L}}\right)+P\left(p_{\mathrm{L}}, R\right)\left(v_{\mathrm{B}}\left(q_{\mathrm{L}}\right)\right) .
$$

Let us also assume that sellers accept high prices with certainty, so the buyer's expected utility when he observes high quality and offers high price for it with probability $P_{i}\left(p_{\mathrm{H}} \mid q_{\mathrm{H}}\right)$ is

$$
\begin{aligned}
\mathbb{E}\left[u_{\mathrm{B}}\left(P_{i}\left(p_{\mathrm{H}} \mid q_{\mathrm{H}}\right)\right)\right]= & P_{i}\left(p_{\mathrm{H}} \mid q_{\mathrm{H}}\right)\left(v_{\mathrm{H}}-p_{\mathrm{H}}\right) \\
& +\left(1-P_{i}\left(p_{\mathrm{H}} \mid q_{\mathrm{H}}\right)\right)\left[P\left(p_{\mathrm{L}}, A\right)\left(v_{\mathrm{H}}-p_{\mathrm{L}}\right)+P\left(p_{\mathrm{L}}, R\right) w_{\mathrm{H}}\right] .
\end{aligned}
$$

The last piece of the model is the link between buyer $i$ 's average probability of offering high price for high quality, $P_{i}\left(p_{\mathrm{H}} \mid q_{\mathrm{H}}\right)$, and the seller's forecasted probability of being offered a high price, $P\left(p_{\mathrm{H}}\right)$.

In the dynamic equilibrium approximation, let $P_{-i}\left(p_{\mathrm{H}} \mid q_{\mathrm{H}}\right)$ be the average probability from the other $n-1$ buyers in the market of offering high price for high quality. In this case, let the average probability of high price that sellers observe be

$$
P\left(p_{\mathrm{H}}\right)=(1-\delta)\left((1-\lambda) P_{-i}\left(p_{\mathrm{H}} \mid q_{\mathrm{H}}\right)+\lambda P_{i}\left(p_{\mathrm{H}} \mid q_{\mathrm{H}}\right)\right),
$$

where $\lambda$ is the effect buyer $i$ has on the total probability of high price in the population of buyers. So for example, in the impunity treatments, if sellers correctly calculate the historical probability of high price, then $\lambda=\frac{1}{n}$, where $n$ is the total number of buyers. In the dynamic equilibrium approximation, sellers use (9) in (5)(7) when they make their production and acceptance decisions. The buyer solves (8) to find her average equilibrium probability of offering high price for high quality. Let buyer $i$ 's average equilibrium probability of offering high price for high quality when the other $n-1$ buyers use $P_{-i}\left(p_{\mathrm{H}} \mid q_{\mathrm{H}}\right)$ be

$$
P_{i,-i}^{*}\left(p_{\mathrm{H}} \mid q_{\mathrm{H}}\right)=\underset{P_{i}\left(p_{\mathrm{H}} \mid q_{\mathrm{H}}\right)}{\arg \max } \mathbb{E}\left[u_{\mathrm{B}}\left(P_{i}\left(p_{\mathrm{H}} \mid q_{\mathrm{H}}\right)\right)\right] .
$$

\subsubsection{Reputation}

Consider a setting in which a seller, rather than observing the history $P\left(p_{\mathrm{H}}\right)$ for the entire market, observes instead seller-specific history, $P_{i}\left(p_{\mathrm{H}}\right)=(1-\delta) P_{i}\left(p_{\mathrm{H}} \mid q_{\mathrm{H}}\right)$, for the seller $i$ with whom she is matched in the current period. This implies $\lambda=1$, and (9) becomes

$$
P\left(p_{\mathrm{H}}\right)=(1-\delta) P_{i}\left(p_{\mathrm{H}} \mid q_{\mathrm{H}}\right) .
$$

In other words, $P_{i}\left(p_{\mathrm{H}}\right)$ is buyer $i$ 's reputation. Intuitively, as $\lambda$ increases, buyer $i$ benefits more from offering a high price for high quality because he captures more of the future benefits.

Proposition 3 (Reputation) In the dynamic equilibrium approximation, $P_{i,-i}^{*}\left(p_{\mathrm{H}} \mid q_{\mathrm{H}}\right)$ increases in $\lambda$.

Proof See Appendix A.

Corollary $1 P_{i,-i}^{*}\left(p_{\mathrm{H}} \mid q_{\mathrm{H}}\right)$ is higher when reputation information is available than when it is not available. 
Proof Follows from the fact that $\lambda$ is higher when reputation information is available.

In summary, $P_{i,-i}^{*}\left(p_{\mathrm{H}} \mid q_{\mathrm{H}}\right)$ is increasing in $\lambda$. Moreover, reputation information increases its value.

\section{Experimental design and hypotheses}

\subsection{Experimental design}

We designed a laboratory setting in which the hold-up problem would be present in the single-shot game (consistent with Proposition 1). In all experimental treatments, we set parameters at $\delta=0.2, e_{\mathrm{S}}=e_{\mathrm{B}}=2, v_{\mathrm{H}}=14, v_{\mathrm{L}}=7, c=4, p_{\mathrm{H}}=9, v_{\mathrm{S}}=5$, and $p_{\mathrm{L}}=5.5$. This means that if the quality is high and the buyer offers a high price, both players earn $5\left(\pi_{\mathrm{B}}=\pi_{\mathrm{S}}=5\right)$, if the quality is high and the buyer offers a low price that the seller accepts, then $\pi_{\mathrm{B}}=14-5.5=8.5$ and $\pi_{\mathrm{S}}=5.5-4=1.5$. If the quality is low and the buyer offers a high price that the seller accepts, then $\pi_{\mathrm{B}}=7-9=-2$ and $\pi_{\mathrm{S}}=9-4=5$. If the quality is low and the buyer offers a low price that the seller accepts, then $\pi_{\mathrm{B}}=7-5.5=1.5$ and $\pi_{\mathrm{S}}=5.5-4=1.5$. If the seller rejects, then $\pi_{\mathrm{S}}=5-4=1$ in all treatments.

Our experimental treatments vary in the effects seller rejection have on the profit of the buyer. In the impunity condition, we set $w_{\mathrm{L}}=2$ and $w_{\mathrm{H}}=9$, and in the reciprocity condition, we set $w_{\mathrm{L}}=w_{\mathrm{H}}=1$. Thus, if the seller rejects, then in the impunity condition $\pi_{\mathrm{B}}=9$ if the quality is high and $\pi_{\mathrm{B}}=2$ if the quality is low (making the seller worse off from rejecting in relative terms as well as in absolute terms), while in the reciprocity condition $\pi_{\mathrm{B}}=1$ regardless of quality (so the seller is worse off in absolute terms, but better off in relative terms). Figure 2 provides experimental parameters in the extensive form of the game. See appendix for experimental instructions.

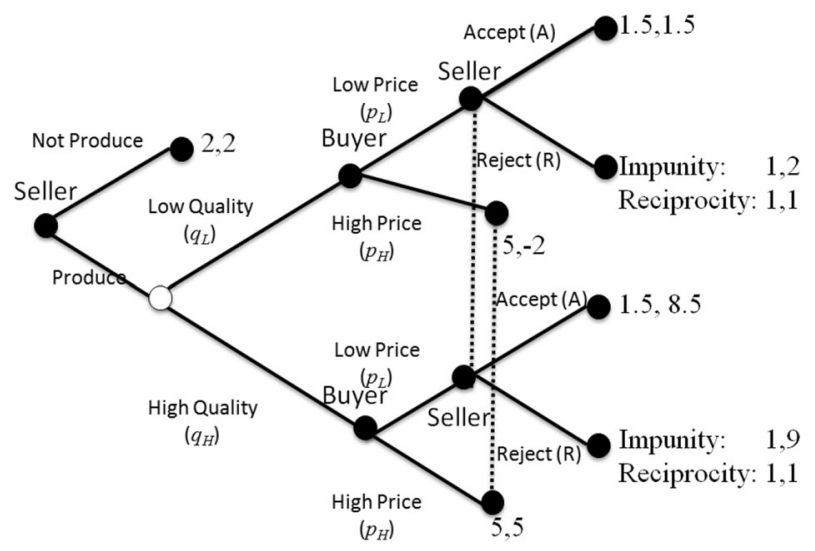

Fig. 2 Extensive form representation of the game in the laboratory experiment 


\subsection{Experimental treatments}

The experiment includes three treatments. In all treatments, we randomly assign participants to buyer and seller roles when they arrive at the laboratory, and they keep the roles for the duration of the session. Each treatment includes four sessions, and each session includes four buyers and four sellers. Participants play the game corresponding to one treatment (with payoffs corresponding to Fig. 2) for 100 rounds. They are randomly re-matched each round. In total, our experiment includes 96 participants. We pay participants a $\$ 5$ show-up fee and an additional amount proportional to their total profits earned in the experiment. Average earnings were $\$ 26.68$ for buyers and $\$ 18.78$ for sellers. We recruited participants using ORSEE recruitment system (Greiner 2004) and offered cash as the only incentive to participate. We designed experimental software using zTree (Fischbacher 2007).

Our design examines the effect of social preferences by comparing impunity and reciprocity conditions. Additionally, we test an intervention that we call reputation, in which we keep track and show to the seller the average number of times the current buyer offered a high price. In summary, our experiment includes the following three treatments:

1. In the impunity treatment, participants have access to their own prior history that includes past production decisions, the price offered (if production occurred), and their own realized profits. The buyers have one additional piece of information that sellers do not have- the realized quality for the current and all past periods.

2. In the reciprocity treatment, the payoffs are different from the impunity treatment - the only difference being in the buyer's payoff that results from seller's rejection. Participants have access to the same historical information as in the impunity treatment.

3. In the reputation treatment, the payoffs are the same as in the impunity condition. Historical information is different. Specifically, sellers see the proportion of the time the buyer with whom the seller is matched during the current period offered a high price; this buyer-specific history is shown to the seller prior to making the production decision.

\subsection{Theoretical predictions and hypotheses}

In this section, we derive theoretical predictions for the behavior in the three treatments.

\subsubsection{The impunity treatment}

In the impunity treatment, a buyer motivated exclusively by monetary payoff derives his average equilibrium probability of offering high price for high quality according to Eqs. (8) and (9).

Figure 3 plots the buyer's equilibrium expected profit as a function of the probability of offering high price for high quality for three levels of $\alpha$ $(\alpha=0, \alpha=0.25$ and $\alpha=1)$, and $\tau=2$ in Fig. 3a and lower levels of $\tau$ in Fig. 3b. 

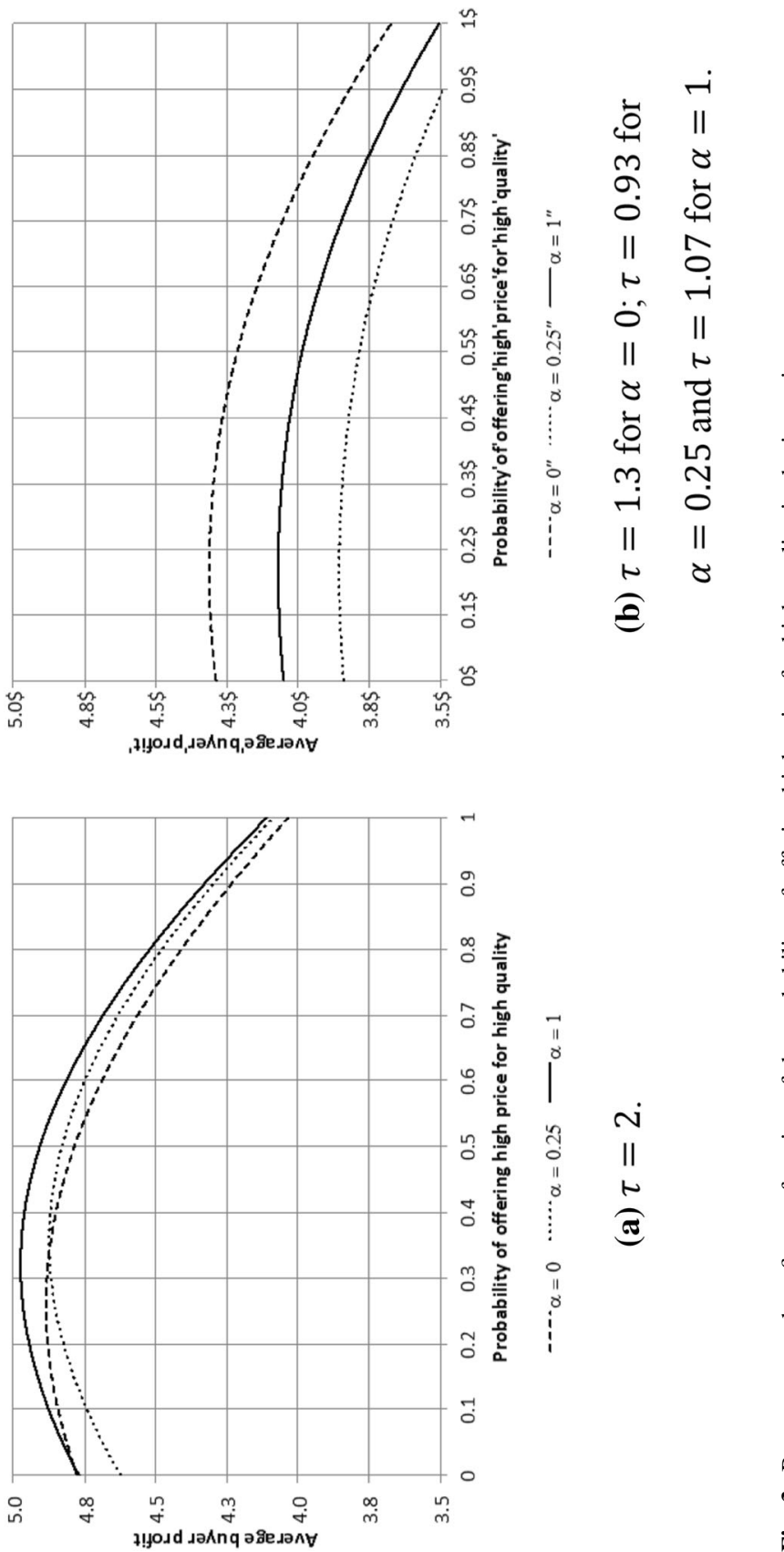

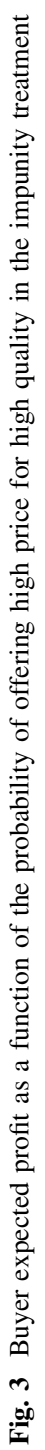


It is easy to calculate that a fully rational seller (very high $\tau$ ) not concerned with inequality aversion $(\alpha=0)$ prefers to produce as long as $P\left(p_{\mathrm{H}} \mid q_{\mathrm{H}}\right)>\frac{2-1.5}{0.8(5-1.5)}=0.1785$, or equivalently $P\left(p_{\mathrm{H}}\right)>0.1428$. For a seller concerned with inequality aversion, this threshold would be higher. A seller with a low $\tau$, however, would produce even for a lower $P\left(p_{\mathrm{H}}\right)$.

Figure 3a shows that when $\tau=2$ (this is the approximate level of $\tau$ we measured in our data), buyer's equilibrium $P^{*}\left(p_{\mathrm{H}}\right)$ ranges from $26 \%$ when $\alpha=0$ to $36 \%$ when $\alpha=0.25\left(P^{*}\left(p_{\mathrm{H}}\right)=0.32\right.$ for $\left.\alpha=1\right)$. Figure $3 \mathrm{~b}$ varies $\tau$ for each level of $\alpha$ so as to make $P^{*}\left(p_{\mathrm{H}} \mid q_{\mathrm{H}}\right)=0.1785$. Here, $\tau$ ranges from 0.93 for $\alpha=0.25$ to 1.3 for $\alpha=0$ ( $\tau=1.07$ for $\alpha=1$ ). Because those levels of $\tau$ are much lower than the levels observed in our data, our first hypothesis predicts positive levels of production and significant probability of high prices given for high quality in the impunity treatment.

Hypothesis 1. In the impunity treatment, buyers offer high prices for high quality on average at least $17.85 \%$ of the time, and sellers sometimes produce. Sellers never reject any price offer.

Whether a seller produces depends on the seller's $\alpha$ and on the $P\left(p_{\mathrm{H}}\right)$ the seller anticipates. The utility from not producing is 2 , while the expected utility from producing is

$$
\mathbb{E}\left[u_{\mathrm{S}}(\text { Produce })\right]=5 P\left(p_{\mathrm{H}}\right)+\left(1-P\left(p_{\mathrm{H}}\right)\right)\left(1.5-7\left(1-\frac{\delta}{1-P\left(p_{\mathrm{H}}\right)}\right) \alpha\right) .
$$

Setting $\mathbb{E}\left[u_{\mathrm{S}}(\right.$ Produce $\left.)\right]$ in Eq. (12) equal to 2 and solving for $\alpha$ characterizes when a fully rational seller produces, i.e.,

$$
\alpha<\frac{5 P\left(p_{\mathrm{H}}\right)+1.5\left(1-P\left(p_{\mathrm{H}}\right)\right)-2}{7\left(1-P\left(p_{\mathrm{H}}\right)\right)-\delta} .
$$

Note that since it is dominated for the buyer to offer a high price for low quality, it follows that $P\left(p_{\mathrm{H}}\right) \leq 1-\delta$. Therefore, the closer $P\left(p_{\mathrm{H}}\right)$ is to $1-\delta$, the closer to certainty it is for the seller to get high price for high quality and the more likely he is to produce regardless of $\alpha$. Generally, we see from (13) that for a fully rational seller, the likelihood of production decreases in $\alpha$ and increases in $P\left(p_{\mathrm{H}}\right)$.

\subsubsection{The reciprocity treatment}

In the reciprocity treatment, rejection is not a dominated action for a seller because even though the seller foregoes 0.5 in absolute profit, he implements the equal split. The seller's utility from rejecting a low price is 1, and based on Eq. (6), his expected utility from accepting a low price is $\mathbb{E}\left[u_{\mathrm{S}}\left(p_{\mathrm{L}}, A\right)\right]=1.5-7 \alpha\left(1-\frac{\delta}{1-P\left(p_{\mathrm{H}}\right)}\right)$, so a fully rational seller whose $\alpha>\frac{0.5}{7}\left(\frac{1-P\left(p_{\mathrm{H}}\right)}{1-P\left(p_{\mathrm{H}}\right)-\delta}\right)$ would reject a low price. This gives buyers an additional incentive to offer a high price for high quality in the reciprocity treatment.

We plot the buyer's expected profit function for three levels of $\alpha$ and $\tau=2$ in Fig. 4. We see from the figure that $P^{*}\left(p_{\mathrm{H}}\right)$ is higher in the reciprocity treatment than 


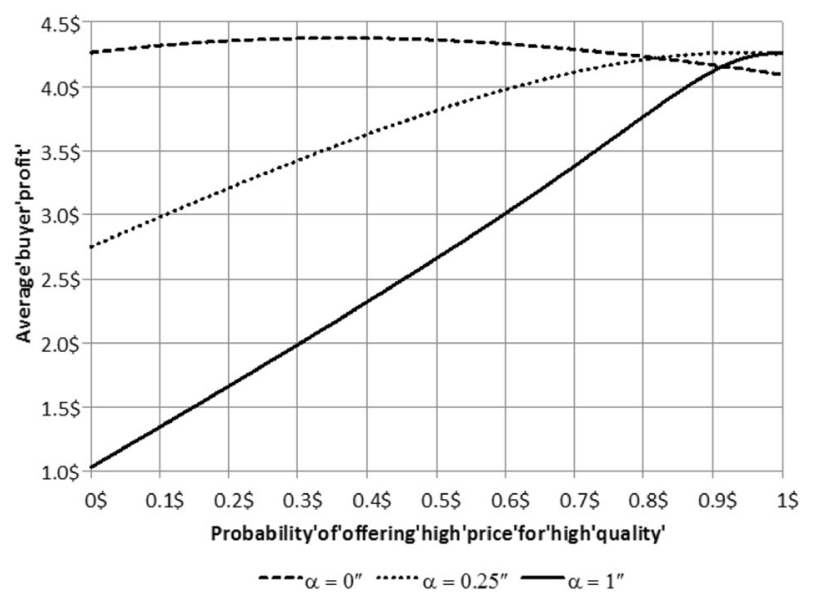

Fig. 4 Buyer's expected profit as a function of the probability of offering high price for high quality in the reciprocity treatment

in the impunity treatment for all three levels of $\alpha$, and the differences are especially pronounced for higher values of $\alpha$.

We summarize predictions about the differences between the impunity and reciprocity treatments in the following hypothesis:

Hypothesis 2. In the reciprocity treatment, the frequency of rejections of low prices will be higher than in the impunity treatment, the frequency of high prices for high quality will be higher than in the impunity treatment, and the production rate will be higher than in the impunity treatment.

\subsubsection{The reputation treatment}

In the reputation treatment, we keep track of each buyer $i$ 's proportion of high prices, denoted $P_{i}\left(p_{\mathrm{H}}\right)$. We use the notation $P\left(p_{\mathrm{H}}\right)$ to denote the average proportion of high prices over the buyers in a cohort. In the reputation treatment, the seller observes the buyer-specific $P_{i}\left(p_{\mathrm{H}}\right)$ prior to deciding whether or not to produce. Knowing $P_{i}\left(p_{\mathrm{H}}\right)$, the seller can use Eq. (5) to decide whether or not to produce for each specific buyer. In the reputation treatment, each buyer controls his own $P_{i}\left(p_{\mathrm{H}}\right)$, in contrast to the impunity treatment, in which each buyer only affects the average $P\left(p_{\mathrm{H}}\right)$ in his group. Therefore, we expect higher proportion of high prices offered for high quality in the reputation treatment than in the impunity treatment, and indeed we can see from comparing Figs. 3 a and 5 that $P^{*}\left(p_{\mathrm{H}}\right)$ is higher in the reputation treatment than in the impunity treatment for all three levels of $\alpha$. A higher $P^{*}\left(p_{\mathrm{H}}\right)$ also implies a higher production rate in the reputation treatment than in the impunity treatment, as we summarize in our last hypothesis.

Hypothesis 3 In the reputation treatment, production and high prices for high quality will be higher than in the impunity treatment. Rejections will be similar across the two treatments. 


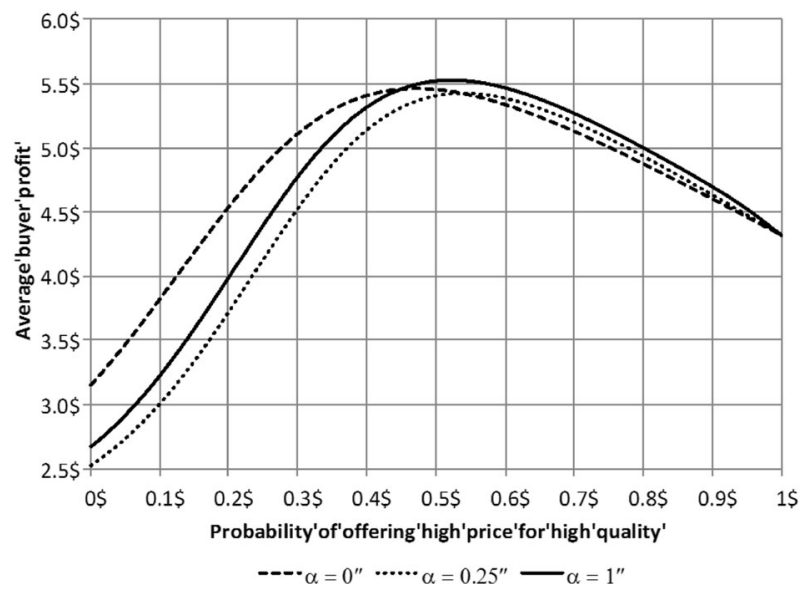

Fig. 5 Buyer's expected profit as a function of the probability of offering high price for high quality in the reputation treatment

\section{Results}

We present summary statistics for production, prices, profits and rejections in the three treatments. We then report estimates for a behavioral model that includes nonmonetary preferences and errors.

\subsection{Summary statistics}

Table 1 reports average rates for production, high prices for high and low quality, rejections and players' earnings. We report standard errors in parenthesis, and we use the session average as a unit of analysis (recall that each treatment includes four sessions).

All $p$ values reported are for a $t$ test with four independent session-level observations. We examine the results as they relate to $\mathrm{H} 1$ pertaining to the impunity

Table 1 Summary statistics

\begin{tabular}{llll}
\hline Probability & \multicolumn{2}{l}{ Treatment } & \\
\cline { 2 - 4 } & Impunity & Reciprocity & Reputation \\
\hline High prices for high quality & $0.256(0.090)$ & $0.695(0.177)$ & $0.589(0.083)$ \\
Production & $0.569(0.156)$ & $0.821(0.183)$ & $0.771(0.126)$ \\
Low prices rejected & $0.140(0.139)$ & $0.527(0.185)$ & $0.105(0.137)$ \\
High prices for low quality & $0.075(0.027)$ & $0.003(0.007)$ & $0.103(0.136)$ \\
High prices rejected & $0.000(0.000)$ & $0.000(0.000)$ & $0.003(0.004)$ \\
Seller earnings & $2.154(0.027)$ & $3.205(0.688)$ & $2.909(0.221)$ \\
Buyer earnings & $4.523(0.469)$ & $3.848(0.344)$ & $4.401(0.335)$ \\
\hline
\end{tabular}

Session is used as a unit of analysis. Each treatment incudes four sessions. Standard errors are in parenthesis 
treatment. As hypothesized, the proportion of high prices given for high quality is significantly above zero in the impunity treatment $(p=0.010)$. In fact, the proportion of high prices for high quality is not significantly different from the hypothesized $0.1785(p=0.168)$, indicating that sellers with low $\alpha$ values are nearly indifferent, on average, between producing and not producing. Last, as predicted, the proportion of production is significantly above zero $(p=0.0053)$. These aspects of the data are consistent with $\mathrm{H} 1$.

However, two aspects of the data are not entirely consistent with the theory. First, the proportion of high prices given for low quality is low, but is significantly above zero $(p=0.012)$. Second, the proportion of rejections is significantly above zero in the impunity treatment $(p=0.011)$. However, both are sufficiently small in absolute terms to be attributed to errors as we will show in the model estimation.

We now turn our attention to $\mathrm{H} 2$, concerned with the comparison of the impunity and reciprocity treatments. We find that the data are consistent with $\mathrm{H} 2$ in that the proportion of high prices given for high quality is significantly higher in the reciprocity treatment than in the impunity treatment $(p=0.004)$, and the proportion of production is higher in the reciprocity treatment than in the impunity treatment (although only weakly significant; $p=0.080$ ).

$\mathrm{H} 3$ is concerned with the comparison of the impunity and reputation treatments. We find the patterns in the data to be consistent with H3. Specifically, the proportion of high prices for high quality in the reputation treatment is above the corresponding proportion in the impunity treatment $(p=0.002)$, and the proportion of production in the reputation treatment is higher than the corresponding proportion in the impunity treatment (weakly so; $p=0.086$ ).

\subsection{Dynamics}

In Fig. 6, we present rejections, high prices offered for high quality, and production rates, as they evolve over time. To focus on the trend, we aggregate 100 periods of data into 20 five-period blocks. Rejections and production are highly stable after an initial learning that takes about 20 periods. The proportion of high prices for high quality is quite stable in rounds $21-80$, but in the reputation treatment, in contrast to the reciprocity treatment, it exhibits end-game effect in the last 20 rounds. This is not surprising; other studies also found end-game effects in reputation treatments (see for example Bolton et al. 2005).

In the next section, we report on estimation of a behavioral model using periods 21-100 for the analysis to eliminate the initial periods of steep learning.

\subsection{Estimation}

In this section, we jointly estimate behavioral parameters $\alpha$ and $\tau$ for the behavioral model presented in Sect. 2.3. We estimate behavioral parameters for sellers only. The buyers are assumed to anticipate seller's reactions, and we capture their decisions with a dynamic equilibrium approximation. Sellers make two decisionsproduction and accept/reject-and these decisions are not independent. The production decision of seller $j$ in period $t$ results in the probability of production 


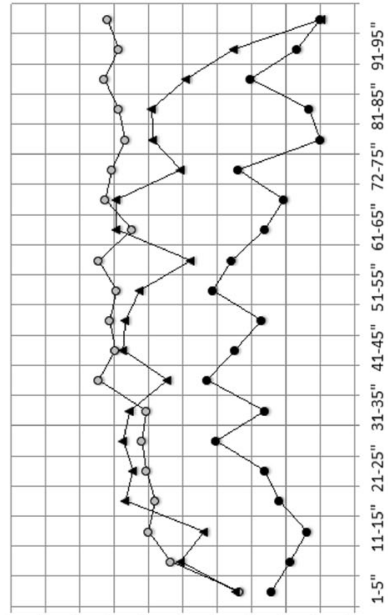

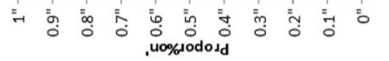

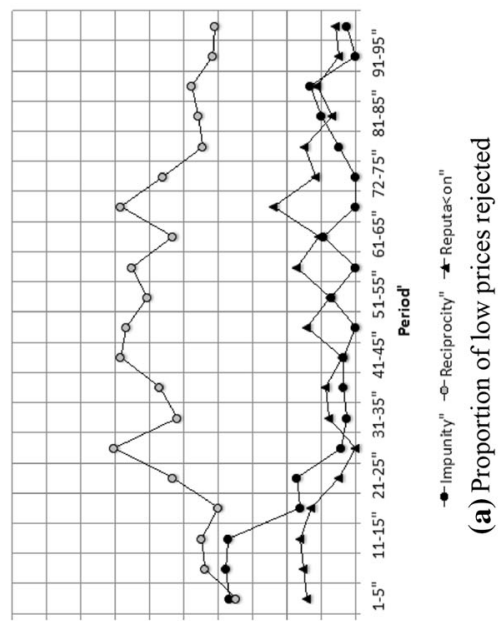

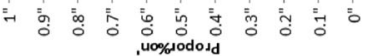
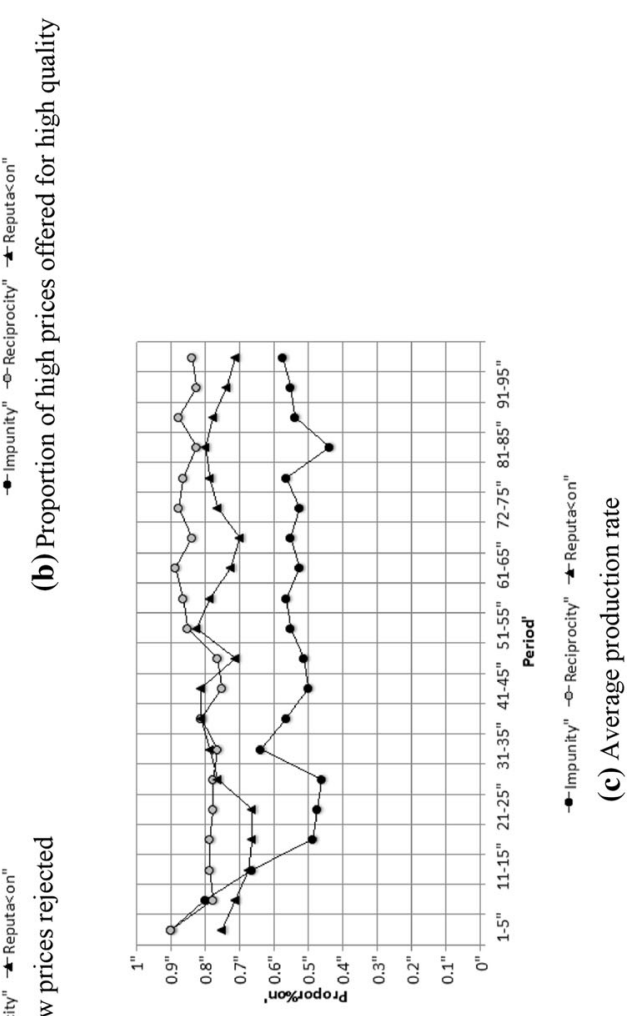

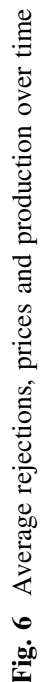

\section{Springer}


$P_{j t}$ (Produce), specified in Eq. (5) (but now indexed by $j$ and $t$ because we are using panel data for estimation). This production decision depends, in turn, on the probabilities of accepting price $p_{k}, k \in\{L, H\}, P_{j t}\left(p_{k}, A\right)$, the seller's second decision is determined by Eq. (7). Because the two decisions are not independent, we estimate them jointly through a joint likelihood function.

Both of the seller's decisions depend on the seller's forecast of the buyer's conditional probability of paying a high price $P_{j i t}\left(p_{\mathrm{H}} \mid q_{\mathrm{H}}\right)$, where $i$ denotes the buyer who has been matched with seller $j$ in period $t$. We assume that in the impunity and the reciprocity treatments, these forecasts are simply the average probability that seller $j$ observed high prices in the past, multiplied by the unconditional probability of high quality. Specifically, in the estimation for impunity and reciprocity treatments, $P_{j i t}\left(p_{\mathrm{H}} \mid q_{\mathrm{H}}\right)=\frac{1}{t-1} \sum_{s=1}^{t-1}\left(P_{j s}=p_{\mathrm{H}}\right)$. Note that subscript $i$ does not appear on the right hand side because the seller cannot distinguish among different buyers in the impunity and the reciprocity treatments. In the reputation treatment, on the other hand, the seller has historical information specific to buyer $i$ : $P_{j i t}\left(p_{\mathrm{H}} \mid q_{\mathrm{H}}\right)=\frac{1}{t-1} \sum_{s=1}^{t-1}\left(P_{j i s}=p_{\mathrm{H}}\right)$.

The joint log-likelihood is defined as

$$
\begin{aligned}
L L & =\sum_{j=1}^{n} \sum_{t=1}^{T}\left[\ln \left(P_{j t}(\operatorname{Pr} \text { oduce })\right) \operatorname{Pr} \text { oduce }_{j t}+\ln \left(1-P_{j t}(\text { Produce })\right)\left(1-\text { Produce }_{j t}\right)\right. \\
& \left.+\ln \left(P_{j t}\left(p_{j t}, A\right)\right) \text { Accept }_{j t}+\ln \left(1-P_{j t}\left(p_{j t}, A\right)\right)\left(1-\text { Accept }_{j t}\right)\right]
\end{aligned}
$$

where $n$ is the total number of sellers in the session $(n=4), T$ is the number of periods in a session $(T=100)$, Produce ${ }_{j t}$ is 1 if seller $j$ decided to produce in period $t$ and 0 otherwise, and Accept ${ }_{j t}$ is 1 if seller $j$ accepted the price the buyer offered in period $t$ and 0 otherwise.

The joint estimation implies that the parameter $\alpha$ is estimated in a way that maximizes the fit not only of the acceptance/rejection decision but also of the production decision. In the impunity and reputation treatments, where it is optimal to always accept, one could expect that the production decision would have the greater influence over the estimate of $\alpha$, whereas in the reciprocity treatment, where acceptance depends largely on inequality aversion, it would be the accept/reject decision that would have the greater impact on the estimate.

We report results of the estimation in Table 2.

The main takeaway from the estimation has to do with the comparison between predicted behavior, based on the estimates of $\alpha$ and $\tau$ under the dynamic equilibrium approximation analyzed in Sect. $2.3^{5}$ (see bottom section of Table 2), and the actual behavior (see Table 1). We stress that even though the dynamic equilibrium approximation model in Sect. 2.3 is only a rough approximation for the actual

\footnotetext{
5 Predicted high prices for high quality are based on solving Eq. (10) for the impunity and reciprocity treatments and Eq. (12) for the reputation treatment. Production probability is based on Eq. (5). Rejection rates are based on Eq. (7). The average buyer's and seller's profits are also based on repeated game equilibrium approximation solution given average behavioral parameters $\alpha$ and $\tau$.
} 
Table 2 Estimation results and predictions based on MLE

\begin{tabular}{llll}
\hline & Impunity treatment & Reciprocity treatment & Reputation treatment \\
\hline Fit & & & \\
$\quad$ Log likelihood & -927.05 & -629.61 & -699.30 \\
Parameters & 3 & 3 & 3 \\
$\chi^{2}$ (restricted $\tau$ ) & $13.068^{* *}$ & $15.38^{* *}$ & $4.19 *$ \\
Estimated parameters & & & \\
$\tau$ Production & $1.562 * *(0.029)$ & $2.633^{* *}(0.141)$ & $1.880^{* *}(0.131)$ \\
$\tau$ Acceptance & $2.342^{* *}(0.162)$ & $1.435^{* *}(0.168)$ & $1.564 * *(0.079)$ \\
$\alpha$ & $0.042^{* *}(0.009)$ & $0.102 * *(0.011)$ & $0.042 * *(0.013)$ \\
Predictionsl MLEs & & & 0.510 \\
High prices for high quality & 0.260 & 0.763 & 0.894 \\
Production & 0.569 & 0.996 & 0.188 \\
Rejection rate & 0.253 & 0.446 & 3.191 \\
Seller profit & 2.285 & 4.115 & 5.383 \\
Buyer profit & 4.562 & 4.275 & \\
\hline
\end{tabular}

$* p<0.05 ; * * p<0.01$

setting, its prediction qualitatively matches virtually all important aspects of the data:

1. Proportions of high prices for high quality and production rates are lowest in the impunity treatment, highest in the reciprocity treatment, and in between in the reputation treatment. None of the high price proportions are different from predictions.

2. Proportions of low prices rejected are highest in the reciprocity treatment, lowest in the reputation treatment, and in between in the impunity treatment. None of the rejection rates are significantly different from predictions.

3. Seller profits are highest in the reciprocity treatment and lowest in the impunity treatment. None of the seller's profits are significantly different from predictions.

4. Buyer's profits are lowest in the impunity treatment. Buyer profits in the impunity and reciprocity treatments are not significantly different from predictions.

The only qualitative difference between predictions and the actual data is that buyer's profits are predicted to be higher in the reputation than in the impunity treatment, while there is no statistically significant difference between them in the data $(p=0.719)$. In fact, average buyer profits in the reputation treatment are significantly lower than predicted $(p=0.031)$.

A deviation from predictions is that quantitatively the proportion of high prices offered for high quality and production rates are slightly lower than predicted in the reciprocity and reputation treatments. This may be due to individual heterogeneity-we computed predictions based on average values of $\alpha$ and $\tau$. In fact, there is a good deal of heterogeneity in behavior (see Appendix B). 
Last, inequality aversion appears low (although significant) in all three treatments. The estimates are lower than estimates reported in the literature (for example, De Bruyn and Bolton (2008) report $\alpha=1.03$ in the linear version of the model - of course they analyze bargaining games that are structurally quite different from ours). In terms of our treatments, estimated $\alpha$ 's are not significantly different between the impunity and reputation treatments $\left(\chi^{2}=0.002, p=0.989\right)$ but are significantly higher in the reciprocity treatment $\left(\chi^{2}=15.51\right.$ for the comparison with impunity and $\chi^{2}=10.89$ for the comparison with reputation; $p<0.001$ for both comparisons). It is possible that inequality aversion is more salient in the reciprocity treatment than in the other two treatments because the seller can implement a fair split by punishing the buyer in that treatment. Saliency of inequality aversion is, however, beyond the scope of this paper.

\section{Conclusion}

With the prevalence of using third party vendors for strategic activities, such as manufacturing, by many major firms, the hold-up problem has to be considered as one of the major pitfalls in supply chain management. For example, contract manufacturers take on increasingly sophisticated tasks and activities requiring relationship-specific investments which leave firms on both sides of the transaction more vulnerable to the hold-up problem than ever before. Additionally, incomplete information is typically present in these arrangements because the OEMs and contract manufacturers are often located on different continents and are subject to different cultural norms.

We analyze and test in the laboratory a stylized game designed to highlight the possibility of the hold-up problem due to the relationship-specific investment by the supplier. We derive approximate equilibrium predictions that match the data remarkably well. In our impunity setting, the analysis predicts limited cooperation but also a large loss in efficiency due to the hold-up problem-predictions that match the data well. We also find, both analytically and empirically, that a setting in which the supplier has the ability to negatively reciprocate, cooperation increases, as does efficiency. Whether or not negative reciprocity is possible is usually not a decision made by the parties but is rather a function of the environment, so we also consider a setting in which we provide to the supplier basic reputation information about the buyers' past actions. We find that reputation information mitigates the hold-up problem, both analytically and empirically.

The managerial implication of our work is that the hold-up problem can be effectively mitigated in settings in which the relationship is not one shot. Most supply chain relationships, even the ones that involve short-term contracts, are not one shot, because information about the firm's past actions tends to become available to the community, even if informally. Our findings suggest that a systematic way of making this reputation information available mitigates the holdup problem a great deal. 
A fruitful direction for future research would be to test other, more sophisticated, reputation system designs. For example, systems that track not just average performance, but also provide information about recent versus past actions, may work even better. It may also be worthwhile to analyze informal arrangements, such as hand-shake agreements, in the context of relationship-specific investments, to learn to what extent they may mitigate the hold-up problem.

Open Access This article is distributed under the terms of the Creative Commons Attribution 4.0 International License (http://creativecommons.org/licenses/by/4.0/), which permits unrestricted use, distribution, and reproduction in any medium, provided you give appropriate credit to the original author(s) and the source, provide a link to the Creative Commons license, and indicate if changes were made.

\section{Appendix A: Proof of Proposition 3}

To find $P_{i,-i}^{*}\left(p_{\mathrm{H}} \mid q_{\mathrm{H}}\right)$, buyer $i$ solves the optimization problem:

$$
\max _{P_{i}\left(p_{\mathrm{H}} \mid q_{\mathrm{H}}\right)} \mathbb{E}\left[u_{\mathrm{B}}\left(P_{i}\left(p_{\mathrm{H}} \mid q_{\mathrm{H}}\right)\right)\right]
$$

We assume that seller does not reject offers when it is dominated to do so in the dynamic setting. Therefore, rejections do not depend on $\lambda$ or on $\left.P_{i}\left(p_{\mathrm{H}} \mid q_{\mathrm{H}}\right)\right)$. Rewriting the objective function for the optimization problem above and setting its decision variable $P_{i}\left(p_{\mathrm{H}} \mid q_{\mathrm{H}}\right)=x$ gives

$$
\begin{aligned}
& \left\{\frac{e^{\left[Y+Z\left((1-\lambda) P_{-i}\left(p_{\mathrm{H}} \mid q_{\mathrm{H}}\right)+x \lambda\right)\right] \tau}}{e^{e_{S} \tau}+e^{\left[Y+Z\left((1-\lambda) P_{-i}\left(p_{\mathrm{H}} \mid q_{\mathrm{H}}\right)+x \lambda\right)\right] \tau}}\right\}\left[\left(v_{\mathrm{H}}-p_{\mathrm{H}}\right) x+\left(v_{\mathrm{H}}-p_{\mathrm{L}}\right)(1-x)(1-\delta)\right. \\
& \left.\quad+C \delta-\left(v_{\mathrm{H}}-p_{\mathrm{H}}\right) x \delta-e_{B}\right]+1,
\end{aligned}
$$

where $C, Y$ and $Z$ are constants that we define to simplify the expressions:

$$
\begin{aligned}
& Y=p_{\mathrm{L}}-c-\alpha\left((1-\delta)\left(v_{\mathrm{H}}-v_{\mathrm{L}}\right)+\left(v_{\mathrm{L}}-2 p_{\mathrm{L}}+c\right)\right), \\
& Z=p_{\mathrm{H}}-p_{\mathrm{L}}-\alpha\left(v_{\mathrm{H}}-2 p_{\mathrm{H}}+c\right)^{+}+\alpha\left(v_{\mathrm{H}}-2 p_{\mathrm{L}}+c\right),
\end{aligned}
$$

and $C=P\left(p_{\mathrm{L}}, A\right)\left(v_{\mathrm{L}}-p_{\mathrm{L}}\right)+P\left(p_{\mathrm{L}}, R\right)\left(w_{\mathrm{L}}\right)=\left(v_{\mathrm{L}}-p_{\mathrm{L}}\right)$.

The first order condition (FOC) of expression (A1) with respect to decision variable $x$ is

$$
\begin{aligned}
& \frac{\left\{\begin{array}{c}
\left.\left(v_{\mathrm{H}}-p_{\mathrm{H}}\right)-\left(v_{\mathrm{H}}-p_{\mathrm{L}}\right)\right) e^{\left[Y+Z\left((1-\lambda) P_{-i}\left(p_{\mathrm{H}} \mid q_{\mathrm{H}}\right)+x \lambda\right)\right] \tau}(1-\delta) \\
+e^{e_{S} \tau}\left[\lambda Z\left(C \delta-e_{B}\right) \tau-\left(v_{\mathrm{H}}-p_{\mathrm{L}}\right)(1-\delta)(1-Z(1-x) \tau \lambda)+\left(v_{\mathrm{H}}-p_{\mathrm{H}}\right)(1-\delta)(1+Z x \tau \lambda)\right]
\end{array}\right\}}{e^{-\left[Y+Z\left((1-\lambda) P_{-i}\left(p_{\mathrm{H}} \mid q_{\mathrm{H}}\right)+x \lambda\right)\right] \tau}\left(e^{\tau e_{S}}+e^{\left(Y+Z\left((1-\lambda) P_{-i}\left(p_{\mathrm{H}} \mid q_{\mathrm{H}}\right)+x \lambda\right)\right) \tau}\right)^{2}} \\
& =0 .
\end{aligned}
$$

Because the denominator is strictly positive, we restrict attention to the numerator denoted as $F(\cdot)$.

According to the implicit function theorem, $x$ is increasing in $\lambda$, iff $\frac{\partial x}{\partial \lambda}=-\frac{F_{\lambda}}{F_{x}}>0$.

We show that $F_{x}$ is negative while $F_{\lambda}$ is positive for $x \leq P_{-i}\left(p_{\mathrm{H}} \mid q_{\mathrm{H}}\right)$, where $F_{x}=\left(e^{\tau e_{s}}+e^{\tau\left(Y+Z\left(x \lambda+P_{-i}\left(p_{\mathrm{H}} \mid q_{\mathrm{H}}\right)-\lambda P_{-i}\left(p_{\mathrm{H}} \mid q_{\mathrm{H}}\right)\right)\right)}\right) Z(1-\delta) \lambda \tau\left(p_{\mathrm{L}}-p_{\mathrm{H}}\right)$, 


$$
\begin{aligned}
F_{\lambda}= & Z \tau e^{\tau\left(Y+Z\left(x \lambda+P_{-i}\left(p_{\mathrm{H}} \mid q_{\mathrm{H}}\right)-\lambda P_{-i}\left(p_{\mathrm{H}} \mid q_{\mathrm{H}}\right)\right)\right)}\left(\left(p_{\mathrm{L}}-p_{\mathrm{H}}\right)(1-\delta)\left(x-P_{-i}\left(p_{\mathrm{H}} \mid q_{\mathrm{H}}\right)\right)\right) \\
& +Z \tau e^{e_{s} \tau}\left\{\delta C+x(1-\delta)\left(v_{\mathrm{H}}-p_{\mathrm{H}}\right)+(1-x)(1-\delta)\left(v_{\mathrm{H}}-p_{\mathrm{L}}\right)-e_{b}\right\} .
\end{aligned}
$$

$F_{x}$ is negative because $Z>0, p_{\mathrm{L}}<p_{\mathrm{H}}$ and $(1-\delta)>0$.

Since $p_{\mathrm{L}}-p_{\mathrm{H}}<0$ for $x \leq P_{-i}\left(p_{\mathrm{H}} \mid q_{\mathrm{H}}\right), \quad$ the $F_{p}$ is positive if $\delta C+$ $x(1-\delta)\left(v_{\mathrm{H}}-p_{\mathrm{H}}\right)+(1-x)(1-\delta)\left(v_{\mathrm{H}}-p_{\mathrm{L}}\right)-e_{B}>0$.

Because

$-(1-x)(1-\delta)<0$, therefore

$$
\begin{aligned}
& -\delta C+x(-1+\delta)\left(v_{\mathrm{H}}-p_{\mathrm{H}}\right)+(-1+x+\delta-x \delta)\left(v_{\mathrm{H}}-p_{\mathrm{L}}\right)+e_{B}<-\delta C \\
& \quad+x(-1+\delta)\left(v_{\mathrm{H}}-p_{\mathrm{H}}\right)+(-1+x+\delta-x \delta)\left(v_{\mathrm{H}}-p_{\mathrm{H}}\right)+e_{B} \\
& \quad=-\delta C+(-1+\delta)\left(v_{\mathrm{H}}-p_{\mathrm{H}}\right)+e_{B}=-\delta\left(v_{\mathrm{L}}-p_{\mathrm{L}}\right)+(-1+\delta)\left(v_{\mathrm{H}}-p_{\mathrm{H}}\right)+e_{B}
\end{aligned}
$$

The above expression is negative, which follows from the assumption that $\delta\left(v_{\mathrm{L}}-p_{\mathrm{L}}\right)+(1-\delta)\left(v_{\mathrm{H}}-p_{\mathrm{H}}\right)>e_{B}$ in Sect. 2.1. We also checked the second order condition of (A1) to verify that the solution of the optimization problem is a maximum by showing that implicit function theorem when $x \leq P_{-i}\left(p_{\mathrm{H}} \mid q_{\mathrm{H}}\right)$ is sufficient for the global maximum.

\section{Appendix B: Individual Heterogeneity}

We calculated average $P\left(p_{\mathrm{H}} \mid q_{\mathrm{H}}\right)$ and $P\left(p_{\mathrm{H}} \mid q_{\mathrm{L}}\right)$ for the buyers, as well as average production and rejection rates for the sellers. Figure 7 shows the distributions of average $P\left(p_{\mathrm{H}} \mid q_{\mathrm{H}}\right)$ and $P\left(p_{\mathrm{H}} \mid q_{\mathrm{L}}\right)$ for individual buyers.

Figure 8 shows the distribution of average production rates for individual sellers.

Figure 9 shows the distribution of average rejection rates for individual sellers. 

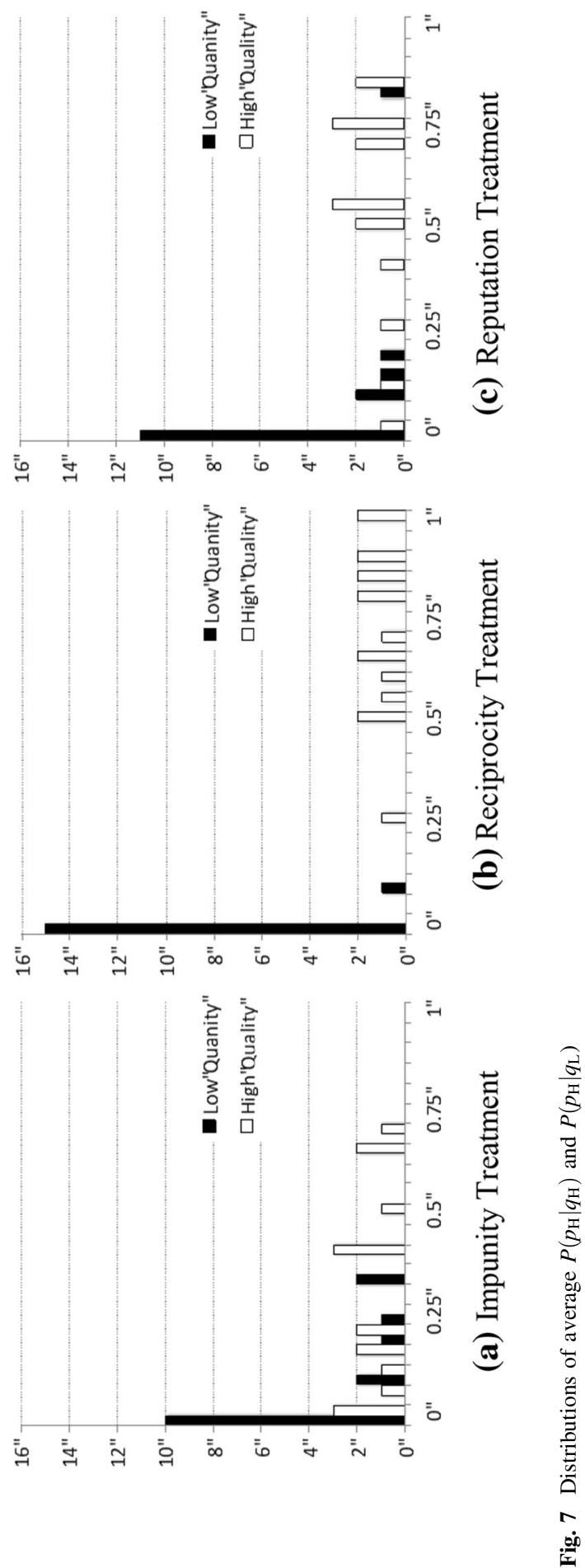

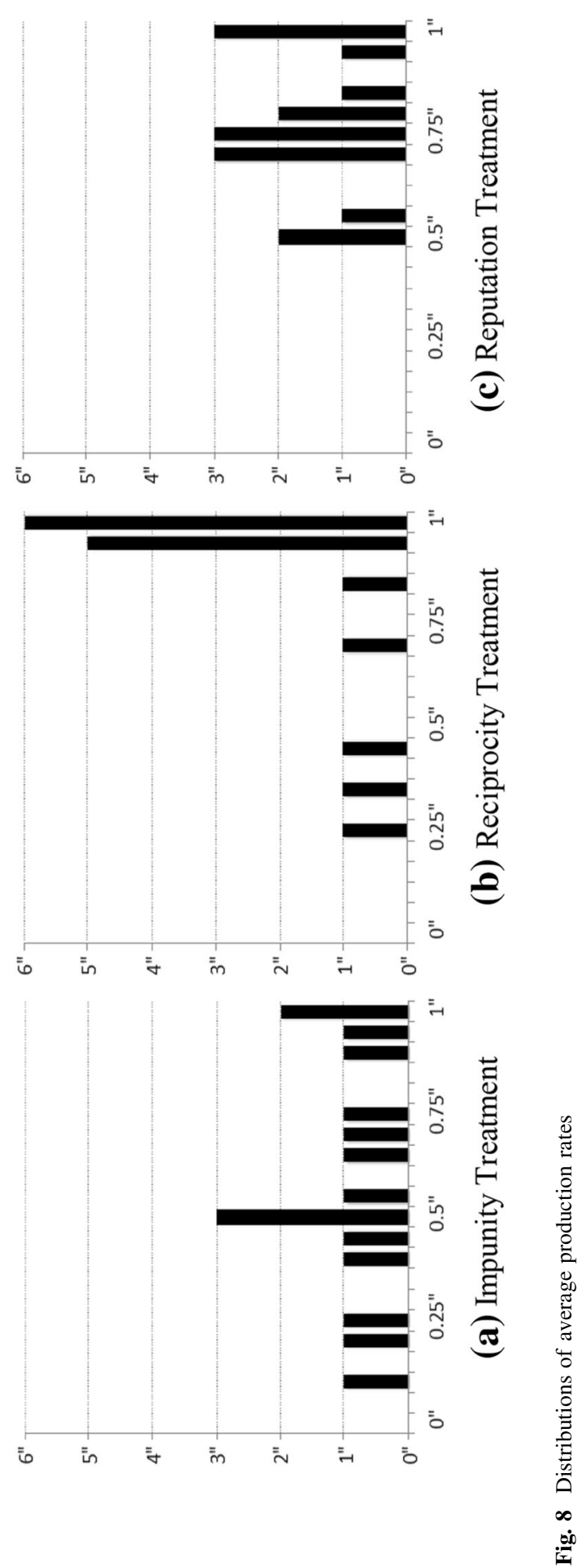

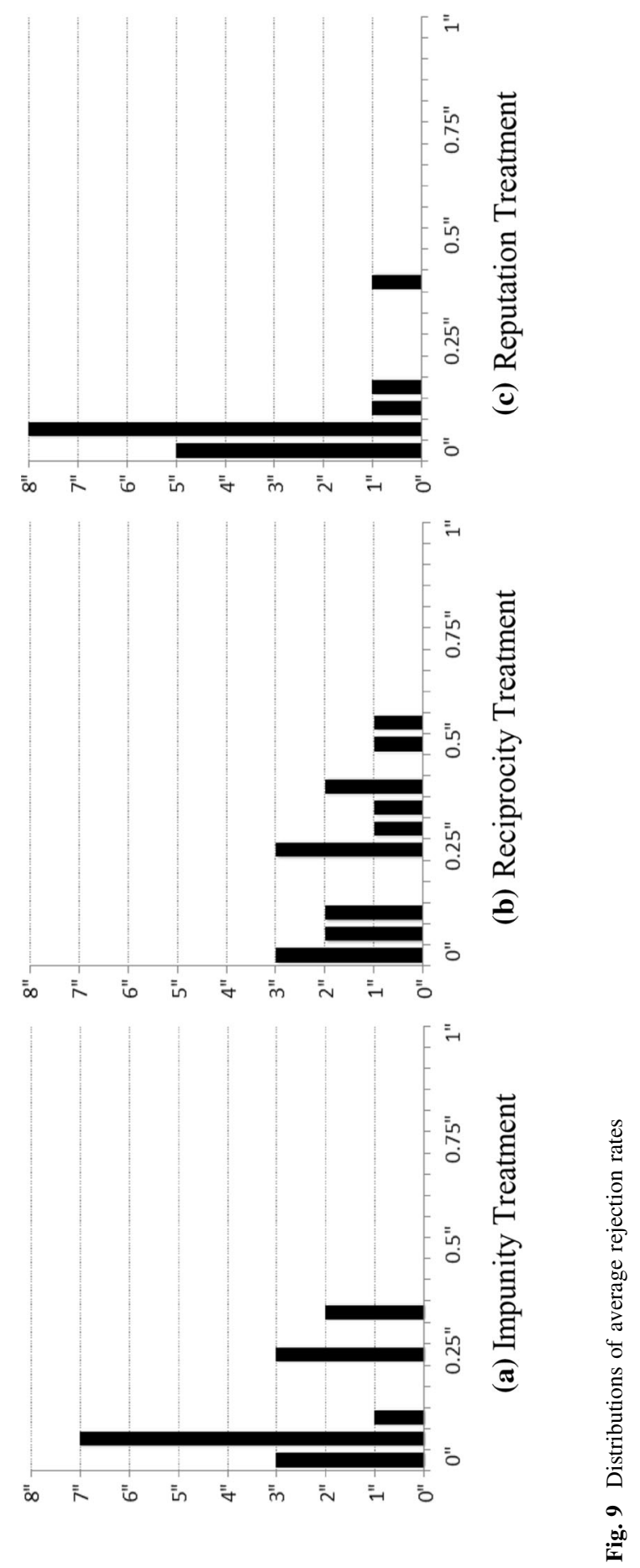


\section{References}

Barnes, A, 2012 Boeing: Faster, faster, faster: The planemaker struggles to fulfill a rush of orders. The Economist January 28, http://www.economist.com/node/21543555. Accessed 07/026/13.

Berg, Joyce, John Dickhaut, and Kevin McCabe. 1995. Trust, Reciprocity and Social History. Games and Economic Behavior 10: 122-142.

Board, Simon. 2011. Relational Contracts and the Value of Loyalty. American Economic Review 101 ((December 2011)): 3349-3367.

Bolton, G.E., and A. Ockenfels. 2000. A theory of equity, reciprocity, and competition. American Economics Review 90 (1): 166-193.

Bolton, G.E., E. Katok, and A. Ockenfels. 2004. How effective are online reputation mechanisms? An experimental study. Management Science 50 (11): 1587-1602.

Bolton, G.E., E. Katok, and A. Ockenfels. 2005. Cooperation among strangers with limited information about reputation. Journal of Public Economics 89 (8): 1457-1468.

Camerer, Colin. 2003. Behavioral Game Theory: Experiments in Strategic Interaction. Princeton: Princeton University Press.

Coase, R. 2006. The Conduct of Economics: The Example of Fisher Body and General Motors. Journal of Economics \& Management Strategy 15 (2): 255-278.

Cooper, D., and J. Kagel. 2015. Other Regarding Preferences: A Selective Survey of Experimental Results. Forthcoming. In The Handbook of Experimental Economics 2, eds. Kagel, J., and A. Roth. Princeton, NJ: Princeton University Press.

Crocker, K.J., and K.J. Reynolds. 1993. The Efficiency of Incomplete Contracts: An Empirical Analysis of Air Force Engine Procurement. The RAND Journal of Economics 24 (1): 126-146.

Cui, T.H., J.S. Raju, and Z.J. Zhang. 2007. Fairness and channel coordination. Management Science 53 (8): 1303-1314.

Cui, Tony Haitao, and Paola Mallucci. 2016. Fairness Ideals in Distribution Channels. Journal of Marketing Research 53 (6): 969-987.

Davis, Andrew and Stephen Leider (2013), Capacity Investment in Supply Chains Contracts and the Hold-up Problem, working paper.

De Bruyn, A., and G.E. Bolton. 2008. Estimating the influence of fairness on bargaining behavior. Management Science 54 (10): 1774-1791.

Dufwenberg, M., A. Smith, and M. Van Essen. 2013. Hold-up: with a Vengeance. Economic Inquiry 51: 896-908.

Duhigg C, Bradsher K (2012) How the U.S. Lost Out on iPhone Work. The New York Times, 1/21/2012. http://www.nytimes.com/2012/01/22/business/apple-america-and-a-squeezed-middle-class.html?page wanted=all\&_r=0. Accessed 9 June 2013.

Ellingsen, T., and M. Johannesson. 2004a. Promises, Threats and Fairness. Economic Journal 114: $397-420$.

Ellingsen, Tore, and Magnus Johannesson. 2004b. Is There a Hold-up Problem? Scandinavian Journal of Economics 106 (3): 475-494.

Fehr, E., and K.M. Schmidt. 1999. A Theory of Fairness, Competition and Cooperation. Quarterly Journal of Economics 114 (3): 817-868.

Fischbacher, U. 2007. z-Tree: Zurich Toolbox for Ready-made Economic experiments. Experimental Economics 10 (2): 171-178.

Gantner A, W Güth, M Königstein. 1998. Equity Anchoring in Simple Bargaining Games with Production, Discussion paper 128, Department of Economics, Humboldt University

Greiner, B. 2004. An online recruitment system for economic experiments. In Forschung und Wissenschaftliches Rechnen. GWDG Bericht 63, ed. K. Kremer, V. Macho Göttingen: Gesellschaft für Wissenschaftliche Datenverarbeitung, 79-93.

Hackett, S.C. 1994. Is Relational Exchange Possible in the Absence of Reputations and Repeated Contact? Journal of Law Economics and Organization 10 (4): 360-389.

Hart O, E Fehr, C Zehnder 2013. Working paper. How Do Informal Agreements and Renegotiation Shape Contractual Reference Points?

Haruvy, E., T. Li, and S. Sethi. 2012. Two-Stage Pricing for Custom-Made Products. European Journal of Operational Research 219 (2): 405-414.

Hoppe, E.I., and P.W. Schmitz. 2011. Can contracts solve the hold-up problem? Experimental evidence. Games and Economic Behavior 73 (1): 186-199. 
Katok, E., and V. Pavlov. 2013. Fairness in supply chain contracts. Journal of Operations Management 31: $129-137$.

Loch, C.H., and Y. Wu. 2008. Social preferences and supply chain performance: An experimental study. Management Science 54 (11): 1835-1849.

MacDonald, G., and M.D. Ryall. 2004. How do value creation and competition determine whether a firm appropriates value? Management Science 50 (10): 1319-1333.

McKelvey, R.D., and T.R. Palfrey. 1995. Quantal Response Equilibrium for Normal Form Games. Games and Economic Behavior 10: 6-38.

Nash, J. 1953. Two-person Cooperative Games. Econometrica 21: 128-140.

Oosterbeek, H., J. Sonnemans, and S. van Velzen. 1999. Bargaining with Endogenous Pie Size and Disagreement Points: A Holdup Experiment. Mimeo: University of Amsterdam.

Özer, O., K. Zheng, and K. Chen. 2011. Trust in Forecast Information Sharing. Management Science 57 (6): 1111-1137.

Özer O, K Zheng, Y Ren. 2013. Forecast Information Sharing in China and the U.S.: Country Effects in Trust and Trustworthiness, Management Science forthcoming.

Reilly S. 2012. Northrop Grumman sues USPS in bitter contract dispute. Federal Times, May 8. http:// www.federaltimes.com/article/20120508/DEPARTMENTS02/205080307/Northrop-Grumman-suesUSPS-bitter-contract-dispute. Accessed 07/026/13.

Rogerson, W. 1992. Contractual Solutions to the Hold-Up Problem. Review of Economic Studies 59 (4): 774-794.

Schone, M. 2011. After Work Stopped on Jet Engine, GE Blasts Competitor Pratt Whitney, ABC News, 3/25. http://abcnews.go.com/Blotter/work-stopped-jet-engine-ge-blasts-competitor-pratt/story?id= 13219559. Accessed 07/026/13.

Sonnemans, J., R. Sloof, and H. Oosterbeek. 2001. On the Relation between Asset Ownership and Specific Investments. Economic Journal 111 (474): 791-820.

$\mathrm{Su}$, X. 2008. Bounded rationality in newsvendor models. Manufacturing \& Service Operations Management 10 (4): 566-589.

von Siemens, F.A. 2009. Bargaining under incomplete information, fairness, and the hold-up problem. Journal of Economic Behavior \& Organization 71 (2): 486-494.

Publisher's note Springer Nature remains neutral with regard to jurisdictional claims in published maps and institutional affiliations. 